https://doi.org/10.48009/1_iis_2007_15-23

\title{
STUDENT'S PERCEPTION OF THE BENEFITS AND USE OF ONLINE TEACHING \& LEARNING
}

\author{
Dr. Amine Nehari Talet, King Fahd University of Petroleum \& Minerals, nehari@kfupm.edu.sa
}

\begin{abstract}
The new millennium heralds exciting opportunities to diversify the ways in which we offer education. We can now offer greater flexibility through online access to learning -- when, where and how we do it. Breaking the shackles of tradition empowers all learners, as their diverse needs are increasingly accommodated in educational programs that are supported by information technology. This paper examines the students' perceptions of the benefits and the efficient use of Online Teaching and Leaning (OTL) in one of the AASCB Accredited Schools. Specifically, this study investigates if there are statistically significant differences in the benefits and the use of OTL among students with different GPAs. The analyses were based on a sample of one hundred and ninety-two students, drawn randomly from the student population at the College of Industrial Management (CIM) of King Fahd University of Petroleum \& Minerals (KFUPM). The analyses showed that there were no significant differences in the OTL benefits among students with different GPAs. It also showed that there were partially significant differences in the use of OTL. The findings have many implications for students and administrators on the implementation and the use of OTL in different disciplines.
\end{abstract}

Keywords: Online Teaching \& Learning (OTL), Face To Face (F2F), the benefit, the use.

\section{INTRODUCTION}

The terms "distance education" and "distance learning" are the conventional terms usually used interchangeably to refer to a form of study that is not based on face-to-face education. Online education is an extension of distance education/learning, but differs from all previous models as being mostly based on screen and keyboard rather than on pen and paper.
Educational Institutions in developing countries are trying to emulate the Western style of integrating technology in the educational processes. Considerations are given to introduce OTL in many of these institutions. The success in using technology in the educational processes the Western world does not necessarily mean that replication in other parts of the world will gain the same success. The specific characteristics of Middle Eastern higher educational institutions would require the adaptation of these characteristics when it comes to knowledge transmission. This becomes especially important in the case of these countries that have different cultural, social, economical and political conditions.

A number of published studies in the Western world investigated the use and benefits of OTL. The results of many of these studies reflect positive conclusions and recommendations as to the appropriateness, advantages, disadvantages, problems and structure of OTL. See for example, Abrahamson, [6]; Besser and Donahue, [4] ; Brown, [5]; Rahm \& Reed, [25]; Twigg, [31]; Dede, [9], Feenberg, [11], Schlough \& Bhuripanyo, [27], Treleaven [30] Unfortunately similar studies have not been conducted in the Middle East..

We notice that most of the Western studies mentioned above placed more emphasis on the positive aspects of OTL. Little has been done on the problems that high educational institutions face with implementing OTL. As mentioned earlier, with the exception of the study of Abouchedid \& Eid [1], nothing has been done in this area of inquiry in the Middle East part of the world.

The objective of this paper is two-fold: firstly, we are interested in studying students' perceptions of the benefits and use of OTL. Secondly, we are interested in students' perceptions of the use of OTL for different types of courses.

The study is therefore unique in that it addresses one of the very important issues facing higher educational institutions in the Middle East namely the integration of OLT as a delivery mode in knowledge transmission. We strongly believe that The study will help students, instructors, and administrators to understand this issue.

The remainder of this study is organized as follows. In the next section, we review relevant 
literature; section three is about the methodology in which we discuss the design of the questionnaire, sample, data collection, hypotheses analysis and results. The last segment of this paper is The conclusion, limitations of the study, and areas for further research.

\section{RELEVANT LITERATURE REVIEW}

Globalization of social and economic reforms and the narrowing of gaps between different members of the society have resulted in increasing demand for affordable education. This affordable education was developed gradually in terms of distance education since the middle of the eighteenth century in Germany, France and England and then introduced into the USA when it appeared in the 1892 catalogue of the University of Wisconsin Palmer et al, [24]. The continuous aspiration of academics to incorporate technology in the promotion of distance education resulted in a new form of distance education known as 'Online Teaching Learning' (OTL).

Unlike other disciplines the amount of research written on Online Teaching and Learning (OTL) is considered to be very limited and not widespread. Meisel \& Marx [21], they have focused on the Internet as an exciting form of technology that can support learning rather than focusing on whether it actually enhances the learning process itself. Sweeney \& Ingram, [28]. But this limited literature is considered to be rich when comparing the history of OTL to other well-established disciplines. The historical and contemporary intention of OTL was and is to move the conventional paper and pen distance education to screen and keyboard form of education. Some attempts have been made to describe the character of online teaching and leaning "distance education." Among these descriptions those of Bååth [2] and Keegan [18] stand out. Keegan specifies five decisive characteristics of online teaching and learning.

These are:

- The quasi-permanent separation of teacher and learner throughout the length of the learning process (this distinguishes it from conventional face-to-face education);

- The influence of an educational organization both in the planning and preparation of learning materials and in the provision of student-support services (this distinguishes it from private study and teach-yourself programs);

- The use of technical media - print, audio, video or computer -to unite teacher and learner and carry the content of the course;
- The provision of two-way communication so that the student may benefit from or even initiate dialogue (this distinguishes it from other uses of technology in education); and

- The quasi-permanent absence of the learning group throughout the length of the learning process so that people are usually taught as individuals and not in groups, with the possibility of occasional meetings for both didactic and socialization purposes. Keegan ([18])

This intention is a noble intention because it aims at reaching a more diverse population at the time and place that suits them. Hara and Kling [16] stated that "there are many high quality online courses taught today. However, a careful reading of the literature suggests that they are usually taught by highly dedicated and very experienced instructors". This comment by Hara and Kling reflects the spirit of those interested in OTL not as being job seekers but as knowledge providers who care for and are interested in the dissemination of knowledge not only to those who can afford it but also those who are keen to acquire it regardless of their financial, employment and social difficulties and commitments.

Several studies, although limited in number, were conducted that have reflected different viewpoints and issues relating to Online Teaching and Learning. These studies have in fact enriched the growing young literature and established a platform for other researchers to continue the search in widening the scope of OTL as much as solving current and expected future problems.

Some of these studies focused on the nature of OTL with respect to students' isolation in distance education and this includes for example Abrahamson ([6]); Besser and Donahue ([4]); Brown ([5]); Rahm and Reed ([25]); Twigg ([31]); Dede ([9]) and Feenberg ([11]). These studies may appear to be different and independent from each other but in fact they are interrelated and complementing each other as they generally focus on frustration generated by technical problems and anxiety caused by communication methods and restrictions. Although their studies focused on the nature of OTL they identified the communication problem as being a special problem associated with OTL. Other important issues were also highlighted suggesting immediate solutions not only to solve them and eliminate their causes but also to possibly prevent similar future problems, from emerging.

Regardless of the negative observations against OTL we should admit that the pioneers' research in 
distance education has in fact not only enriched education but also provided value added services to those who may never have dreamed of holding university degrees. Furthermore, these OTL research efforts have minimized the difficulties experienced by student and providers of distance education in the Western world and provided solid ground for the commencement of OTL research in other cultures.

Modern Western distance education courses using the internet as its core communication medium has been documented in the literature and classified under five major groups. Hara and Kling, ([16])

- A specialized research literature, which include journals such as the Journal of Asynchronous Learning and the American Journal of Distance Education, research monographs, and specialized conferences;

- A practitioner literature whose audience is administrators and faculty who may be involved in such courses (e.g., the Chronicle of Higher Education, written advice for instructor);

- Instructional materials for students taking specific courses (e.g., syllabi, oriented documents, tip sheets);

- Popular accounts if such courses written for the public (i.e., the mainstream press); and

- Marketing description of courses and degree programs provided by educational institutions to their prospective students and their parents, employers and others.

Most of the diverse literature, including the specialized research literature, emphasize the likely value of Online teaching \& learning to institutions (for reaching new students and generating new revenues) and to students (for convenience, and possibly enriched educational experiences), although there is some debate about the actual costs (and thus profits) of these new distance education courses. Green, [14]. Amongst academic practitioners, there has also been considerable concern about whether universities or their faculty own the instructional materials that they develop for these courses Noble, [8].

Some of the specialized research studies have examined the difficulties faced by instructors in developing and teaching these courses Besser and Donahue, ([4]); Rahm \& Reed, ([25]) or that students report in taking them Wegerif, [33]; Rossman, [26]. Overall, though, the vast majority of the practitioner and popular articles about Online teaching \& learning tends to emphasize the virtues of Online teaching \& learning and to minimize the difficulties of routinely providing high quality courses to students learning from them. This promotional bias has been characteristic of other practitioner and popular literatures about computerization. Kling, [19].

Another common area of research in online teaching \& learning is investigation into the effectiveness of online delivery of course materials in students' perception and learning outcomes, especially in comparison with the traditional classroom. Schlough and Bhuripanyo ([27]) developed a Web-based instruction program for graduate students at the University of Wisconsin-Stout.

Gagne and Shepherd [12] have supported the common finding of non-significant differences between Online teaching \& learning and conventional classes (conventional face-to-face lecture mode) using a well-described true experimental design, with a relatively larger number of students. The same course was delivered in the traditional format and via the Web. According to Gagne and Shepherd, the online course allowed students to engage in synchronous (chat) and asynchronous (e-mail and forums) interaction to communicate with the instructor and with each other. They were given their own workspaces where they could exchange files with the instructor and with each other. To enhance comparability, the same text, syllabus, assignments and examinations were used in both classes. Moreover, the same lecturer taught both groups.

The focus on outcomes, other than academic grades, is also highlighted in a review of the OTL literature. Treleaven ([30]) notes the importance of the social context in learning by citing phenomenological and ethnographic studies that have examined learning outcomes in OTL. These studies have examined OTL from the perspective of the student's perceptions and experiences, the instructional methodology used to achieve outcomes and the socio-cultural phenomena that support socially constructed learning and meaning.

Research conducted in the Western world focused on the appropriateness, efficiency and effectiveness of introducing OTL in their relevant societies. Research on OTL in societies other than developed countries were not found in Western journals and this was expected as such research should come from within to reflect the particular society and its environment. The importance of local or regional research in OTL is based on the fact that this form of study is considered to be a form of a learning community and 
accordingly, it should not be restricted to the consideration of the willingness to introduce OTL but it should stretch further to include the predication or problems to be encountered and the expected visible and invisible cost and benefits compared with the conventional form of teaching and learning and available human and non-human resources. For such a study to be successful, it should be undertaken and conducted only by those familiar with the environment of its application.

The perception of the student as one of the stakeholders of higher education has not been fully realized in some institutions around the world. This is due, in part, to the formalism surrounding educational systems, which does not promote collaboration from all involved in these systems. Vinten, [23] Instead, students in some cases are considered as the means to maintain the prestige of the institution at the expense of course content and faculty morale. This view is, in part, supported by Kumar and Usunier [20].

\section{RESEARCH METHODOLOGY}

The research centered upon the following research question: Do significant differences exist amongst students with different GPA on the perception of the use and benefit of OTL in one of the AASCB Accredited Schools in Middle East.

\section{Sample}

A questionnaire was developed and pilot tested for the main purpose of this study. It was distributed to five hundred students in different majors at the end of the academic year of 2004-2005. Four-hundred and fifty four were returned three-hundred and one were completed giving a net response rate of $66.30 \%$, of which there were only one hundred and ninety-two responses from the College of Industrial Management (CIM). The third part comprises the important factors for Implementing OTL. The final part includes the expected problems in Using OTL.

\section{Research Variables}

Based on the value of Cronbach's Alpha criterion, this part of the questionnaire did not require any modification. We therefore went for full data collection.

The list of research variables was categorized into two groups. The first group was entitled "the Impact of OTL on students". This group includes the following variables:
- Understanding the material is better with online vs. the traditional way,

- Improve students’ responsibility,

- Improve students' confidence,

- Increase the student knowledge, and

- Help students improve their critical thinking. These variables serve as dependent variables in testing our first hypothesis

The second group is entitled "The use of OTL for the type of courses". This group includes the following variables:

- OTL is suitable for theoretical courses

- $\quad$ OTL is suitable for applied courses

These variables serve as dependent variables in testing our second hypothesis

The rationale for categorizing the list of dependent variables was based on the relevant literatures.

Schlough and Bhuripanyo ([27]) investigated the effectiveness of online delivery of course materials in students' perception and learning outcomes, especially in comparison with the traditional classroom delivery mode. Jiang \& Ting [17] studied the engagement of students to learn through OTL and found that learning in OTL students expressed a preference for using material on their own. Bacani \& Rohfs [3] noted that OTL requires considerable self discipline, organization, responsibility and perseverance.

O'Connor et al. [23] noted that students are usually absent in multimedia online lectures so it requires a lot of effort because "interaction," is an important factor of learning. Demetriadis et al. [10], confirmed that such an environment can make students' interaction with contents more vivid and thus can make students learn more efficiently. Halsne \& Gatta [15] reported that students in OTL spent on average an extra hour per week on class work in comparison to their F2F counterparts. Treleaven ([30]) focused on outcomes, rather than academic grades Garrison, Cleveland-Innes, \& Fung [13] suggested that students do see a difference in the learning process and a need for their role adjustment. Online learning should be viewed as more cognitive or internally oriented.

\section{Reliability Analysis}

Since the research instrument was originally designed for this study, all the constructs were subjected to scale reliability analysis using Cronbach's Alpha criterion. For newly developed constructs Cronbach' Alpha of .70 is considered adequate for this type of exploratory study Cronbach, L. J [7], Nunnally, J. C.[22]. The study shows that Cronbach's Alpha of .79 
for the use and the benefit of OTL construct. This indicates that the construct is internally consistent and highly reliable.

\section{Research question \& Hypotheses}

In this paper, we hypothesize that there will be no significant differences in the benefit of OTL among CIM students with different GPA. We also hypothesize that there will no significant differences on the use of OTL among the same group of students. We categorize student's GPA in the following four groups:

Group 1 with GPA $>=3$

Group 2 with $3>$ GPA $>2.5$

Group 3 with $2.4>$ GPA $>=2$

Group 4 with $2>$ GPA $>1$

Statistically speaking, Ho1: $\boldsymbol{\mu 1}=\boldsymbol{\mu} \mathbf{2}=\boldsymbol{\mu} \mathbf{3}=$

$\boldsymbol{\mu} \mathbf{4}$ versus the alternative hypothesis that at least one of these group differs in their perception of the benefit of OTL. Similarly, Ho2: $\boldsymbol{\mu} \mathbf{1}=\boldsymbol{\mu} \mathbf{2}=\boldsymbol{\mu}$ 3= $\boldsymbol{\mu} \mathbf{4}$ versus the alternative hypothesis that at least one of these group differs in their perception for the use of OTL

The items in both groups were operationalized on a five point Likert type scale ("1"= Strongly Agree, "2"= Agree, "3"= Neutral, "4" Disagree, "5" Strongly Disagree).

To test The hypotheses we first examined all variables using the "explore" procedure of "SPSS14.0". The purpose of this analysis was to ensure that all variables do not violate the normality and homogeneity of variance assumptions. It was necessary to decide on whether or not we should use parametric statistics. Since none of these variables violated the normality and the homogeneity of variance assumptions we used parametric statistics. Secondly, the analysis proceeded in two steps. We first run some descriptive statistics on the profile of respondents (GPA, major, mother tongue). In step two, ANOVA was used to test the above hypotheses.

\section{RESULTS}

In this part of the analyses we discuss the profile of respondents in terms of GPA, major, and mother tongue.

\section{Majors}

Table 1 indicates that more than fifty percent of the respondents are majoring in MIS. More than twenty three percent are majoring in marketing and around twelve percent in accounting, more than nine percent in finance, and about five percent in management. The sample is dominated by students majoring in
MIS. Since the MIS majors in the school of business more versed in the use of information system and information technology, it gives us more validity in the response.

Table 1. Distribution of the respondents in majors

\begin{tabular}{l|l|l|}
\hline Majors & Frequency & Percent \\
\hline MIS & 98 & 51.04 \\
\hline ACCT & 22 & 11.46 \\
\hline MGT & 9 & 4.69 \\
\hline MKT & 45 & 23.44 \\
\hline FIN & 18 & 9.38 \\
\hline Total & 192 & 100 \\
\hline
\end{tabular}

\section{GPA}

Table 2 below shows that about fifty seven percent of the students have a GPA level between 2.0 and 2.4, about twenty percent have a GPA between 2.5 and 3.0, seventeen percent have a GPA level above 3.0, and around six percent are between 1.and 2.00. The sample is dominated by students between 2.0 and 2.4 .

Table2. Distribution of the respondents in GPA

\begin{tabular}{c|c|c|}
\hline GPA & Frequency & Percent \\
\hline GPA $>=3$ & 33 & 17.19 \\
\hline $3>$ GPA $>2.5$ & 39 & 20.31 \\
\hline $2.4>$ GPA $>=2$ & 109 & 56.77 \\
\hline $2>$ GPA $>1$ & 11 & 5.73 \\
\hline Total & 192 & 100.00 \\
\hline
\end{tabular}

M

\section{Mother Tongue}

As table $\mathbf{3}$ indicates, ninety two percent students are Arabic speaking, while the remaining are non-Arabic speaking students.

Table3. Distribution of the respondents by mother tongue

\begin{tabular}{l|l|l|}
\hline Mother tongue & Frequency & Percent \\
\hline Arabic speaking & 176 & 91.67 \\
\hline Non Arabic speaking & 16 & 8.33 \\
\hline Total & 192 & 100.00 \\
\hline
\end{tabular}

Current literature on OTL lack classification of the OTL benefits in students' GPA. This motivated us to fill this void by doing such a classification presented in table 4. In the process of grouping the OTL benefits in the GPA, The intention was to see if the students in developing countries with different GPAs would perceive the benefits differently. 
Table 4. Mean and standard deviation for the five variables measuring the perceived benefits of OTL

\begin{tabular}{|c|c|c|c|c|c|c|c|c|c|c|}
\hline \multirow{3}{*}{$\begin{array}{l}\text { Student's perception } \\
\text { on the Benefits of OTL }\end{array}$} & \multicolumn{2}{|c|}{ GPA $>=3$} & \multicolumn{2}{|c|}{$3>$ GPA $>2.5$} & \multicolumn{2}{|c|}{$2.4>$ GPA $>=2$} & \multicolumn{2}{|c|}{$2>$ GPA $>1$} & \multicolumn{2}{|c|}{ Sample } \\
\hline & \multicolumn{2}{|c|}{$\mathrm{N}=33$} & \multicolumn{2}{|c|}{$N=39$} & \multicolumn{2}{|c|}{$\mathrm{N}=109$} & \multicolumn{2}{|c|}{$N=11$} & \multicolumn{2}{|c|}{$\mathrm{N}=192$} \\
\hline & Mean & Stdv & Mean & Stdv & Mean & Stdv & Mean & Stdv & Mean & Stdv \\
\hline $\begin{array}{l}\text { Understanding material } \\
\text { better }\end{array}$ & 2.94 & 1.11 & 3.2 & 1.12 & 3.00 & 1.00 & 3.54 & .82 & 3.07 & 1.09 \\
\hline $\begin{array}{ll}\text { Improve } & \text { student's } \\
\text { responsibility } & \\
\end{array}$ & 2.02 & 1.07 & 2.36 & 1.13 & 2.02 & .95 & 1.91 & .83 & 2.09 & 1.00 \\
\hline $\begin{array}{ll}\text { Improve } & \text { student's } \\
\text { confidence } & \end{array}$ & 2.03 & .96 & 2.20 & .95 & 2.23 & .99 & 2.18 & .75 & 2.19 & .96 \\
\hline $\begin{array}{ll}\text { Increase } & \text { student's } \\
\text { knowledge } & \\
\end{array}$ & 2.6 & .99 & 2.82 & 1.07 & 2.73 & 1.10 & 2.91 & .83 & 2.74 & 1.06 \\
\hline $\begin{array}{l}\text { Help students to } \\
\text { improve their thinking } \\
\text { skills }\end{array}$ & 2.15 & 1.06 & 2.1 & .96 & 2.23 & .97 & 2.18 & .75 & 2.2 & .97 \\
\hline
\end{tabular}

Table 4 shows the mean and standard deviation for the five variables measuring the perceived benefits of OTL as cross tabulated by students' GPAs. In understanding the material better, students with the highest GPA tend to agree that benefit, while students with lower GPA tend be neutral on this benefit. It is natural that excellent students would be appreciative of a new delivery mode such as OTL. As for the remaining benefits, students tend to agree on the impact of OTL on these benefits regardless of the GPA. The findings are in congruence with the current literature. It is even more important to mention that students in developing countries perceive these benefits like any other students in any part of the world. In essence these four benefits are universally accepted

Table 5. Mean and standard deviation for the five variables measuring the perceived use of OTL

\begin{tabular}{|c|c|c|c|c|c|c|c|c|c|c|}
\hline \multirow{3}{*}{$\begin{array}{l}\text { Student's perception } \\
\text { on the Use of OTL }\end{array}$} & \multicolumn{2}{|c|}{ GPA $>=3$} & \multicolumn{2}{|c|}{$3>$ GPA $>2.5$} & \multicolumn{2}{|c|}{$2.4>$ GPA $>=2$} & \multicolumn{2}{|c|}{$2>$ GPA $>1$} & \multicolumn{2}{|c|}{ Sample } \\
\hline & \multicolumn{2}{|c|}{$N=33$} & \multicolumn{2}{|c|}{$N=39$} & \multicolumn{2}{|c|}{$N=109$} & \multicolumn{2}{|c|}{$N=11$} & \multicolumn{2}{|c|}{$N=192$} \\
\hline & Mean & Stdv & Mean & $S t d v$ & Mean & Stdv & Mean & Stdv & Mean & Stdv \\
\hline $\begin{array}{l}\text { Only for theory } \\
\text { courses }\end{array}$ & 2.12 & 1.21 & 2.35 & 1.26 & 1.92 & 1.02 & 2.91 & 1.30 & 2.10 & 1.14 \\
\hline $\begin{array}{l}\text { Only for applied } \\
\text { courses }\end{array}$ & 3.81 & .95 & 3.87 & .92 & 3.67 & 1.07 & 3.45 & 1.03 & 3.72 & 1.02 \\
\hline
\end{tabular}

Table 5 shows that the mean and the standard deviation for the two variables comprising the use of OTL. For the use of OTL in theoretical courses, students regardless of their GPA, tend to agree on the use of OTL. On the other hand, students tend to disagree about the use of OTL in applied courses. The rational is that the material in theory based courses can easily be grasped by students regardless of the medium of instruction. Applied courses may need hands-on and more interaction with the instructor.

\section{Analysis of Variance (ANOVA)}

The ANOVA analyses were run to test the two hypotheses. In table 6 the data clearly indicated that there are no significant differences among CIM student's with different GPA levels with regards to the five benefits in utilizing OTL. Thus Hypothesis One cannot be rejected. The results are supported by previous studies. For example Bacani and Rohfs ([3]) noted that OTL requires considerable self discipline, organization, responsibility and perseverance. Jiang and Ting ([17]) also found that learning in OTL students expressed a preference for using material on their own (a significant correlation with level of students' participation. Halsne and Gatta ([15]) reported that students in OTL spent on average an extra hour per week on class work in comparison to their face to face (F2F) counterparts.

\begin{tabular}{|c|c|c|c|c|c|c|}
\hline ANOVA & & $\begin{array}{l}\text { Sum of } \\
\text { Squares }\end{array}$ & df & Mean Square & $\mathrm{F}$ & Sig. \\
\hline \multirow{3}{*}{ Better understanding of the material } & Between Groups & 4.1639 & 3 & 1.3880 & 1.1863 & 0.3162 \\
\hline & Within Groups & 219.9559 & 188 & 1.1700 & & \\
\hline & Total & 224.1198 & 191 & & & \\
\hline Improve student's responsibility & Between Groups & 3.7242 & 3 & 1.2414 & 1.2298 & 0.3002 \\
\hline
\end{tabular}




\begin{tabular}{|c|c|c|c|c|c|c|}
\hline \multirow{5}{*}{ Improve student's confidence } & Within Groups & 189.7706 & 188 & 1.0094 & & \\
\hline & Total & 193.4948 & 191 & & & \\
\hline & Between Groups & 1.1066 & 3 & 0.3689 & 0.3968 & 0.7555 \\
\hline & Within Groups & 174.7632 & 188 & 0.9296 & & \\
\hline & Total & 175.8698 & 191 & & & \\
\hline \multirow{2}{*}{ Increase the student's knowledge } & Between Groups & 0.9213 & 3 & 0.3071 & 0.2703 & 0.8467 \\
\hline & Within Groups & 213.5734 & 188 & 1.1360 & & \\
\hline \multirow{4}{*}{$\begin{array}{l}\text { Help students to improve their thinking } \\
\text { skills }\end{array}$} & Total & 214.4948 & 191 & & & \\
\hline & Between Groups & 0.3242 & 3 & 0.1081 & 0.1137 & 0.9520 \\
\hline & Within Groups & 178.7539 & 188 & 0.9508 & & \\
\hline & Total & 179.0781 & 191 & & & \\
\hline
\end{tabular}

Table 6. ANOVA test about the benefits of OTL with regard to CIM student's GPA

The data displayed in table 7 partially supported Hypothesis 2. There is a significant difference between CIM student's GPA and the use of OTL in theoretical courses. However there are no significant differences among CIM student's GPA levels with regard to applied courses. Terrell [29] reported that students with a preference for systematic planning and abstract conceptualization of a situation were more likely to succeed, than students preferring

Table 7. ANOVA test about the use of OTL with regard to the type of courses

\begin{tabular}{|c|c|c|c|c|c|c|}
\hline ANOVA & & Sum of Squares & $\mathrm{df}$ & $\begin{array}{l}\text { Mean } \\
\text { Square }\end{array}$ & $\mathrm{F}$ & \\
\hline \multirow{3}{*}{ Only for theory courses } & Between Groups & 13.1052 & 3 & 4.3684 & 3.4389 & 0.018 \\
\hline & Within Groups & 238.8114 & 188 & 1.2703 & & \\
\hline & Total & 251.9167 & 191 & & & \\
\hline \multirow{4}{*}{ Only for Applied courses } & Between Groups & 2.1599 & 3 & 0.7200 & 0.6844 & 0.563 \\
\hline & Within Groups & 197.7568 & 188 & 1.0519 & & \\
\hline & Total & 199.9167 & 191 & & & \\
\hline & Total & 243.8698 & 191 & & & \\
\hline
\end{tabular}

\section{CONCLUSIONS}

Online Teaching and Learning has proved to be an efficient way of communicating with students. It is also a convenient form of education, especially for working people and those with extensive commitments. Literature has demonstrated that students perceive OTL as being a beneficial form of transmitting knowledge. This was due to the rapid rise in the development of technologies and decreasing costs of electronic hard and software.

In this study we attempted to investigate if there are significant differences in students' perception about the benefit of OTL among students with different GPAs. We also tried to examine if there concrete experience and interaction with other students are significant differences in the use of OTL among the same group of students.

The results showed that there are no significant differences among CIM student's with different GPA in reference to the following five benefits:

- Understanding the material is better with online vs. traditional way,

- Improve students' responsibility,

- Improve students' confidence,

- Increase the student knowledge, and

- Help students improve their critical thinking. 
There were also no significant differences among CIM student's with different GPA with regards to the use of OTL for applied courses, but there were significant difference among the same group in the use of OTL in theory-based courses. Students with an average GPA between 2.00 and 2.4 are aware that OTL improves their responsibility, confidence, and thinking skills. Lower GPA students are not in favor of OTL either for applied or theory based courses.

This study has many implications for CIM students, and administrators at KFUPM. The findings can help the college administrators to decide on the implementation and the use of OTL in different disciplines.

Having different perspectives on the subject of OTL not only enhances knowledge transmission but also helps academic institutions to put in

\section{REFERENCES}

1. Abouchedid, K. \& Eid, M.George. Elearning challenges in the Arab world: revelations from a case study profile. Quality Assurance in education, vol 12 Number 1 pp 15-27 (2004)

2. Bååth, J.A. On the nature of distance education. Distance Education 2, 2, 212-219 (1981)

3. Bacani, C. \& Rohlfs, O. Click here for a Diploma. Asiaweek, (22 June 2000). http:// www.asiaweek.com/asiaweek/features/universiti es2000/artic_online.html

4. Besser H., \& Donahus S. Introduction and Overview, Journal of the American Society for Information Science: Perspectives on . . . distance independent education, 47 (11): 801804. 1996.

5. Brown K. M. The role of internal and external factors in the discontinuation of offcampus students, Distance Education, 17 (1), pp. 44-71.( 1996)

6. Craig E. Abrahamson. Issues in interactive communication in distance education, College Student Journal, 32 (1), pp. 33-42 (1998).

7. Cronbach, L. J. Coefficient alpha and the internal structure of tests. Psychometrika, 16, 297-333(1951)

8. David F. Noble, Digital diploma mills: The automation of higher education. (October, 1997). Available at place efficient and effective educational programs.

However, there are limitations to this study and therefore the results cannot be generalized. In order to get a better understanding of OTL we need to survey students, instructors, academic administrators and technicians on the related issues to implement OTL. Since the study considers only one group (i.e. Students), the findings are applicable to the institutions we studied.

\section{Acknowledgment}

I would like to thank College of Industrial Management at King Fahd University of Petroleum and Minerals for its generous support.

http://www.firstmonday.org/issues/issue4_7/whi $\underline{\text { te/ }}$

9. Dede C. Emerging Technologies in distance education for business, Journal of education for business, 71 (4), pp. 197-205 (1996)

10. Demetriadis, S., Triantfillou, E., and Pombortsis, A. A phenomenon graphic study of students' attitudes toward the use of multiple media for learning, Proceedings of the 8th annual conference on Innovation and technology in computer science education, 2003.

11. Feenberg A., Computer conferencing and the humanities, Instructional Science, 16 (2), pp. 169-186

12. Gagne, Margaret, and Morgan Shepherd. Distance Learning in Accounting. The Journal Technological Horizons in Education. (April 2001)

13. Garrison, B., Cleveland-Innes, M. \& Fung, T. Student role adjustment in online communities of inquiry: Model and instrument validation [Electronic version]. Journal of Asynchronous Learning Network, 8 (2), 61-74. (2004).

14. Green K.C. Drawn to the Light, Burned by the Flame? Money, Technology and Distance Education. ED11 (5):J1-J8 (May, 1997)

15. Halsne, A. \& Gatta, L. Online versus traditionally-delivered instruction: A descriptive study learner characteristics in a community college setting. Online Journal of Distance Learning Administration, Volume V, Number I, Spring 2002 available http://www.westga.edu/ distance/ojdla/spring51 halsne51.html

16. Hara, N. and R. Kling. Students' Frustrations with a Web-Based Distance 
Education Course. First Monday. Vol. 4 No. 12

- (December 6th 1999) at http://www.firstmonday.dk/issues/issue4_12/ind ex.html

17. Jiang, $\mathbf{M}$ \& Ting, E. Course Design, Instruction, and Students' Online Behaviors: A study of Instructional Variables and students' perceptions of online learning. Paper presented at the Annual Meeting of the American Educational Research Association, (April 13-17 1998). SanDiego, CA.

18. Keegan, D. Foundations of distance education. 2nd ed. London: Routledge, 1991

19. Kling, R. Reading 'All About' Computerization: How Genre Conventions Shape Nonfiction Social Analysis, The Information Society 10(3) (February 1994):147$172 . \quad$ Available: http://www.slis.indiana.edu/kling/read94a.html 20. Kumar, R., Usunier, J.C. Management education in a globalizing world: lessons from the French experience, Management Learning, Vol. 32 No.3, pp.363-92. (2001).

21. Meisel, S. Marx, B. Screen to screen versus face to face: Experiencing the differences in Management education. Journal of Management Education, 23(6), 719-731 (1999).

22. Nunnally, J. C. Psychometric theory ( $2^{\text {nd }}$ Ed.). New York: McGraw-Hill. 1978

23. O'Connor, C., Sceiford, E., Wang, G., and Foucar-Szocki, D. "Departure, Abandonment, and Dropout of E-learning: Dilemma and Solutions," TechLearn 2003 Conference, 2003.

24. Palmer R. D, Collins R. A \& Roy P. Direction in Distance Education, (1996)

25. Rahm D. \& Reed B. J. Tangled webs in public administration: Organizational issues in distance learning." Public Administration and Management: An Interactive Journal, 3 (1)
(1998). Available at http://www.pamij.com.rahm.html

26. Rossman, M. H. Successful Online Teaching using an Asynchronous Learner Discussion Volume 3, Issue 2 - (November 1999)

27. Schlough, S. \& Bhuripanyo, S. The Development and Evaluation of the Internet Delivery of the Course 'Task Analysis', SITE 98: Society for Information Technology \& Teacher, Proceedings of the Education International Conference, (March 10-14 1998)., Washington, DC

28. Sweeney, J \& Ingram, D. A comparison of traditional and web based tutorials in marketing education: An exploratory study Journal of Marketing Education, 23 (1), 345-352 (2001).

29. Terrell, $\mathbf{S}$ The effect of learning style on doctoral course completion in a Web-based learning environment. The Internet and Higher Education, 5(4), 345-352 (2002).

30. Treleaven, L. A new taxonomy for evaluation studies of online collaborative learning .In T. Roberts (Ed), Online Collaborative Learning. Queensland Science Publishing.pp.160-180 (2003)

31. Twigg C. A. Is Technology a Silver Bullet? Educom Review (March/April), 28-29, (1997).

32. Vinten, G. "The business school in the new millennium", The International Journal of Educational Management, Vol. 14 No.4, pp.18091(2000).

33. Wegerif R., "The social dimension of asynchronous learning networks", Journal of Asynchronous Learning Networks, 2 (1), (1998) [On-line], Available at http://www.aln.org/alnweb/journal/vol.2_issue1/ wegerif.htm 